\title{
Intrahepatic Bile Duct Cancer TNM Finding v8
}

National Cancer Institute

\section{Source}

National Cancer Institute. Intrahepatic Bile Duct Cancer TNM Finding v8. NCI Thesaurus.

Code C134577.

A finding about one or more characteristics of intrahepatic bile duct cancer, following the rules of the TNM AJCC v8 classification system. This staging system applies to intrahepatic cholangiocarcinomas, combined hepatocellular-cholangiocarcinomas (mixed hepatocholangiocarcinomas), and primary neuroendocrine tumors of the liver. Primary sarcomas of the liver, pure hepatocellular carcinomas, hilar cholangiocarcinomas, and gallbladder carcinomas are not staged using this staging system. (from AJCC 8th Ed.) 